\title{
FEEA
}

\section{Currency Crises and Political Factors: \\ Drawing Lessons from the EMS Experience}

\author{
by \\ Francisco Pérez-Bermejo * \\ Simón Sosvilla-Rivero ** \\ DOCUMENTO DE TRABAJO 2004-04
}

March 2004

$\begin{array}{ll}* & \text { FEDEA. } \\ \text { ** } & \text { FEDEA y Universidad Complutense de Madrid. }\end{array}$

Los Documentos de trabajo se distribuyen gratuitamente a las Universidades e Instituciones de Investigación que lo solicitan. No obstante están

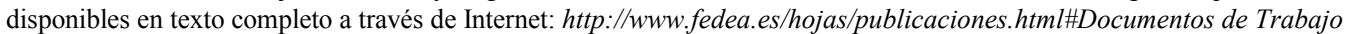

These Working Documents are distributed free of charge to University Department and other Research Centres. They are also available through Internet: http://www.fedea.es/hojas/publicaciones.html\#Documentos de Trabajo 
Depósito Legal: M-3416-2004 


\title{
Currency Crises and Political Factors: Drawing Lessons from the EMS Experience*
}

\author{
Francisco Pérez-Bermejo ${ }^{\dagger}$ \\ FEDEA \\ Simón Sosvilla-Rivero \\ FEDEA \& Universidad Complutense de Madrid
}

March, 2004

\begin{abstract}
This paper analyses the functioning of the European Exchange Rate Mechanism (ERM). To that end, we apply duration models to estimate an eclectic specification that enables us to explicitly incorporated political and institutional factors into the explanation of European exchange rate policies. The estimations are based on quarterly data of eight currencies participating in the ERM, covering the complete history of the European Monetary System. Our results suggest that both economic and political factors are important determinants of the ERM currency policies. Concerning economic factors, the real exchange rate, the interest differentials and the central parity deviation would have negatively affected the duration of a given central parity, while credibility, the level of international reserves and the price level in the anchor country would have positively influenced such duration. Regarding political variables, elections, central bank independence and left-wing administrations would have increased the probability of maintaining the current regime, while unstable governments would have been associated with more frequent regime changes. Moreover, we show how the political augmented model outperforms, both in terms of explanatory power and goodness of fit, the model which just incorporates pure economic determinants.
\end{abstract}

JEL classification numbers: C41, D72, F31, F33

Key Words: Duration analysis, Political variables, Exchange rates, European Monetary System

\footnotetext{
${ }^{*}$ We would like to thank Reyes Maroto for her contribution in an early stage of this paper. We are also grateful to the participants in the $57^{\text {th }}$ International Atlantic Economic Conference for helpful comments and suggestions.

${ }^{\dagger}$ Corresponding authors: Francisco Pérez-Bermejo, FEDEA, C/ Jorge Juan, 46, 28001 Madrid, Spain; tel: 00349143504 01; Fax 00349157795 75; email: fperez@fedea.es. Simón Sosvilla-Rivero, FEDEA, C/ Jorge Juan, 46, 28001 Madrid, Spain; tel: 003491435 04 01; Fax 00349157795 75; email: sosvilla@fedea.es.
} 


\section{Introduction}

In recent times certain experiences such as the turbulence of the European Exchange Rate Mechanism (ERM onwards) in 1992-93, the Turkish lira crises in 1994 and 2001, the collapse of the Mexican peso in 1994, the East Asian turmoil during 1997-98, the Russian currency disturbances in 1998, or the crisis of the Brazilian real in 1999, have renewed the interest in the analysis of the potential causes behind currency crises. Accordingly, an extensive literature sprung up to explore the underlying factors behind such phenomena. Two are the predominant strands of research, the so-called First and Second Generation currency crises models. First Generation models argue that exchange rate crises occur when economic fundamentals deteriorate beyond a point that is consistent with the maintenance of a currency peg. (see Krugman, 1979). On the other hand, Second Generation models emphasize the key role played by self-fulfilling expectations in explaining currency crises (see Obsfield, 1994). In a recent work, Maroto-Illera, Pérez-Bermejo and Sosvilla-Rivero (2002) have built an eclectic model that significantly improves the traditional explanations about the functioning of the European Monetary System (EMS hereafter), by exploiting complementarities among these two mainstreams.

Notwithstanding the useful insights provided by these economic models, some recent research (see Mélitz, 1994; Bussière and Mulder, 1999) has demonstrated how the explicit incorporation of political and institutional factors into the analysis of currency crisis, improves considerably the explanatory power of just pure economic models. In spite of the suggestive evidence provided by these works, the application of the developments of the growing Political Economy literature has been largely restricted to the analysis of inflation, public debts or budget deficits (see Grilli et al., 1991; Roubini and Sachs, 1988) and, when applied to the analysis of currency crises, focused on the case of emerging economies.

Consequently, the aim of this paper is to combine these two lines of research (the influence of political variables and the currency crises literature) by mixing into a unique model the economic factors suggested by the two highlighted economic frameworks with some political and institutional factors, to provide a deep understanding of the functioning of the European ERM, the centrepiece of the EMS. To that end, we depart from the previous papers by using duration analysis to examine the survival of the central parities in the ERM. We have applied this approach using quarterly data on eight countries participating in the ERM covering the complete EMS history (1979-1998) ${ }^{1}$.

Concerning the political and institutional factors, two questions explored in the Political Economy literature are of special interest for our investigation:

- Do politicians try to (artificially) stimulate the economy before elections?

- Are there systematic differences in the policies implemented by parties of

\footnotetext{
${ }^{1}$ The closer work is the paper from Eichengreen, Rose and Wyplosz (1995) who investigated the impact of some political variables (left-wing governments, elections, change in government, past and future government victory or defeat, new finance minister) on the exchange rate regimes of 20 OECD countries between 1959 and 1993, by means of event-study methodology
} 
different ideological orientation?

The first question has been deeply explored by the Opportunistic models [see Nordhaus (1975), Lindbeck (1976), Rogoff and Sibert (1988), Rogoff (1990) or Persson and Tabellini (1990), among others], which analyse the incentives of politicians to manipulate the economy in the period just before an election, typically by means of expansionary policies. The analysis of the second question is the focus of the so-called Partisan models [see Hibbs (1977) and Alesina (1987)], which investigate the relationship between the macroeconomic policies implemented and the ideological orientation of the government. Typically, right-wing parties care about inflation and attach lower weights to unemployment, while left-wing are more willing to bear the costs of inflation to fight unemployment.

Moreover, it is interesting to note that the study of the so-called "Political Business Cycles" for the European case could be even more revealing than for the American case, since in the US the election dates are fixed and pre-established. By contrast, in the majority of the European countries the election dates are chosen by the ruling party while it is still governing. Therefore, one would expect that the government would select the election date in such a way that it coincides with a favourable economic situation that would favour the government's popularity. Furthermore, the European case is also interesting since the process toward a Economic and Monetary Union (EMU afterwards) would have either changed the incentives or impose severe restrictions over preferences for the different political parties (for example socialist parties giving more weight to the control of inflation in their political agendas).

In incorporating the political factors into the analysis we have profited from the results of our previous work (Maroto-Illera et al., (2002)) which just considers pure economic factors. This is in line with other previous papers (see Bussière and Mulder, 1999; Mulder et al., 2002) which make use of well-performed economic models as useful benchmarks for assessing the importance of the political variables. As an example, the work from Bussière and Mulder (1999) incorporates some political variables into the previous work from Tornell (1998), improving both the power to explain and predict economic crises of the original economic model.

The paper proceeds as follows. Section 2 briefly describes the methodology of duration model approach. In Section 3 we describe the data set used to capture the potential determinants of the survival of the central parities in the ERM, while Section 4 reports the empirical results. Finally, some concluding remarks are provided in Section 5 . 


\section{Econometric Methodology: Duration Analy- sis}

In this section, we offer a brief description of the main concepts and functions used in the duration analysis. This methodology is not new in economics. Various Labor Economics studies have applied this technique to investigate the factors that explain the observed exit/entry rates into the unemployment (a good example is the work from Bover et al, 1997). Other applications include the field of Industrial Organization, for example McCloughan and Stone (1998), who examine the life duration of some multinational subsidiaries in the UK.

Duration analysis is particularly suitable for the analysis of data which have two main characteristics: (1) the dependent variable is the waiting time until the occurrence of a well-defined event, and (2) there are some explanatory variables whose effect on this waiting time we wish to assess. In this paper we are going to relate these "well-defined" events with the changes of regime occurred within the ERM.

In the characterization of $T$, the (non-negative) random variable representing time $^{2}$, two functions play a central role: the survivor function, $S(t)$, defined as the complement of the c.d.f. ${ }^{3}$, represents the probability of "surviving" past time $t$. On the contrary, the hazard function, $h(t)$, gives the (instantaneous) rate of occurrence of the event; that is, the probability that the phenomenon of interest is observed at time $t$. These two functions may be related by the following expression:

$$
h(t)=\frac{f(t)}{S(t)}
$$

In words, the rate of occurrence of the event at duration $t$ equals the density of events at $t$, divided by the probability of surviving to that duration without having experienced the event. When the hazard is not constant we say that the process exhibits duration dependence. Assuming that $h(\cdot)$ is differentiable, there will be positive (negative) duration dependence at time $t$ if $[d h(t) / d t]>0$ $([d h(t) / d t]<0)$. With positive (negative) duration dependence, the probability of observing a change increases (decreases) as time passes.

As a first approximation to study the spells between two consecutives changes, we can restrict our analysis to just the time elapsed without considering the effects of any other additional covariates; this is often cited as the non-parametric analysis and consists on the estimation of the empirical (i.e. unconditional) hazard and survivor functions.

\footnotetext{
${ }^{2}$ More precisely, $T$ is assumed to be a non-negative continuous random variable with probability density function (p.d.f.) $f(t)$ and cumulative distribution function (c.d.f.) $F(t)=[\operatorname{Pr}$ $T \leq t]$

${ }^{3}$ The exact definition of the survival function is: $S(t)=\operatorname{Pr}[t>T]=1-F(t)=\int_{t} f(x) d x$
} 
As equation (1) shows, for each duration t, the empirical hazard is the proportion of cases that have survived up to $t$ that change exactly in that moment. The product-limit Kaplan-Meier (see Kaplan and Meier, 1958) method is usually employed to compute this function according to the formula:

$$
\widehat{h}(t)=\frac{c_{t}}{d_{t}}
$$

where $c_{t}$ is the number of cases that changes at time $t$ and $d_{t}$ is the surviving population up to that instant.

With respect to the survivor function, the maximum-likelihood KaplanMeier estimator of the cumulative survivor function is defined according to:

$$
\widehat{S}(t)=\prod_{j \mid t_{j} \leq t}\left(\frac{d_{j}-c_{j}}{d_{j}}\right)
$$

Typically in economics, we will be more interested in estimating the effects of additional regressors on the expected hazard rates. This is the so-called parametric analysis where the two predominant approaches developed for modelling the additional effects are the Proportional Hazard ( $\mathrm{PH})$ and the Accelerated Failure-Time (AFT) models.

The first family of models, introduced by Cox (1972), provides an appealing setting to asses the influence of additional regressors on the hazard function. More precisely, the hazard at time $t$ for an individual $i$ with characteristics $x_{i}^{\prime}$ is assumed to be:

$$
h_{i}\left(t \mid x_{i}^{\prime}\right)=h_{0}(t) \exp \left(x_{i}^{\prime} \beta\right)
$$

where $h_{0}(t)$ is the baseline hazard function. Note how this specification clearly separates the effect of time, captured by the baseline function, from that of the covariates, which is reflected either as a proportional increase or decrease in the hazard.

Different PH models are obtained depending on the assumption made about the functional form of the baseline. For example, if our data exhibits a nonconstant hazard rate the Weibull distribution would be an appropriate choice; in this case, the baseline function is given by the following expression:

$$
h_{0}(t)=\theta t^{\theta-1}
$$

where the ancillary parameter, $\theta$, captures the duration dependence; note that when this parameter is greater than one, the hazard will increase with time 
(i.e. positive duration dependence) while if were lower then as time passed the hazard rate would decease indicating a negative dependence.

The Exponential distribution is a particular case of the Weibull when the ancillary parameter equals one. This case assumes that the influence of time is constant over time as the baseline reduces to:

$$
h_{0}(t)=1
$$

Hence, this distribution is suitable for modeling data with a constant hazard (i.e. no duration dependence).

An alternative method consists on leaving the baseline hazard completely unspecified and estimating the parameters using a partial likelihood function. This approach was proposed by Cox (1972) and may be helpful for checking the robustness of the results obtained from that a Weibull or an Exponential model.

The AFT approach proposes an alternative method to model the influence of additional variables on the waiting-time, namely running a simple regression where the dependent variable is the logarithm of the survival time. More precisely:

$$
\log T_{i}=x_{i}^{\prime} \beta+\varepsilon_{i}
$$

where $\varepsilon_{i}$ is an error term whose distribution have to be specified. As in the $\mathrm{PH}$ setting, different models are obtained by assuming different distributions for the error term.

A large fraction of papers in the literature of currency crises have attempted to shed light on the variables that determine the (observed) probability of experiencing an episode of crisis $^{4}$. Since the $\mathrm{PH}$ models focus on the hazard function, whose connection with the concept of probability is quite clear, they provide a suitable framework for relating economic and political factors with the regime changes observed alongside the ERM history. Thus, in the empirical section of the paper we will make use of this particular class of parametric models.

\footnotetext{
${ }^{4}$ The pioneer work in this area is the paper form Blanco and Garber (1986), focused on the Mexican crisis of the early 1980s. Typically, probit/logit models are used in the empirical exercises undertaken in all these works
} 


\section{The Data}

\subsection{The Dependent Variable}

In our study we use quarterly data of eight currencies participating in the ERM of the EMS: the Belgian franc (BFR), the Danish crown (DKR), the Portuguese escudo (ESC), the French franc (FF), the Dutch guilder (HFL), the Irish pound (IRL), the Italian lira (LIT) and the Spanish peseta (PTA). Given the role of Germany as the nominal anchor of the EMS (see Bajo-Rubio et al., 2001), our exchange rates are expressed vis-á-vis the Deustchemark. The sample period runs from the first quarter of 1979 to the fourth quarter of 1998, covering the complete history of the System.

As we have seen, duration analysis requires the definition of two key variables: one that accounts for the occurrence of the event under study (i.e. the indicator of the regime changes) and other which measures the time elapsed between consecutive changes (i.e. the duration of each regime).

The indicator of the regime changes is constructed using a dummy, which takes the value one whenever a regime change is observed and zero otherwise. For this purpose, we consider that a currency experience a regime change when any of the following situations occur: (1) the currency joins the ERM; (2) a realignment of its central parity is registered; (3) its fluctuation bands are modified $^{5}$. This definition determines the structure of our dataset, although two relevant features need carefully consideration. First, the way in which a change is defined imposes the right-truncation of the data, since the ERM ceased before the last change for each currency had been registered. On the other hand, recall that each currency may experience several regime changes along the sample period; this phenomenon is known as multiple record data or multiple failure-time data. These two questions are appropriately dealt with in all estimations in the paper ${ }^{6}$.

\footnotetext{
${ }^{5}$ For the Italian lira (LIT), we also consider as a change its temporary exit of the system in the third quarter of 1992 and its re-entrance in the fourth quarter of 1996

${ }^{6}$ All estimations were performed using the statistical package STATA 8.1, which permits the appropriate treatment of both multiple-record and right censored data
} 
Concerning duration, we define this variable as the number of quarters elapsed between two consecutive changes. Change and duration define the survival-time data associated with each regime. Their summary statistics are presented in Table 1. As can be seen, for the eight currencies considered we have a total of 154 observations, with the average duration being 6.6 quarters. The average (empirical) probability of change is $42 \%$.

Table 1: Change and Duration. Descriptive statistics

\begin{tabular}{|lcc|}
\hline & \multicolumn{2}{c|}{ ALL CURRENCIES } \\
& Change & Duration \\
\hline \hline Mean & 0.416 & 6.617 \\
Std. Dev. & 0.494 & 5.976 \\
Skewness & 0.34 & 1.004 \\
Min & 0 & 1 \\
Max & 1 & 21 \\
\hline & \multicolumn{2}{|c}{} \\
N. of changes & \multicolumn{2}{|c|}{64} \\
Observations & \multicolumn{2}{c|}{154} \\
\hline
\end{tabular}

Figure 1 plots the duration of the ERM regimens for the entire sample period (1979-1998). As shown, there is a high percentage of short durations (less than 5 quarters), representing the $52 \%$ of the total sample, while long durations (greater than 15 quarters) only account for 9\%. This result shows that the regime changes are frequent in the sample; in particular the number of changes with duration less than 5 quarters is 49 .

Figure 1: Duration of regimes in the EMS (1979-1998)

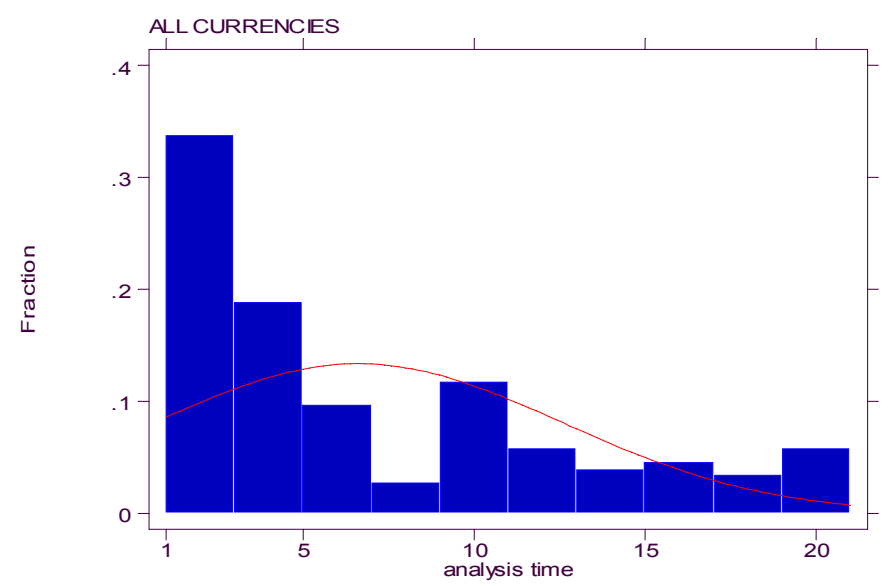




\subsection{Economic Explanatory Variables}

Once the key variables in determining the structure of the survival-time data, have been properly defined, we can focus on the description of the economic and political variables that will be considered in our empirical investigation.

Following the empirical applications of the First Generation models, we consider the following variables as potential economic factors influencing the probability of a regimen change:

1. The current account: The weaker a country's current account, the more difficult it will be to defend the currency in the event of an attack. We use data from the International Financial Statistics (IFS) published by the International Monetary Fund: line 78ald (Current Account, n.i.e.).

2. The price level: A higher price level in Germany would reduce the probability of devaluation through a reduction in inflation differentials with the anchor country. In particular we use data on consumer price index from the IFS (line 64).

3. The production level: One would expect that an increase in the level of output (included in our specification through the industrial production index), would signal stronger economic performance and then would reduce the pressure on the domestic currency, leading to a lower probability of a regime change. We use data on the index of industrial production from the Main Economic Indicators (MEI) published by the Organisation for Economic Co-operation and Development (OECD).

4. The level of international reserves: The empirical evidence suggests that increases in the level of international reserves significantly reduces the probability of a regimen change. We use data from the IFS (line 1l.d).

5. The real exchange rate: An increase in the real exchange rate (which might indicate a loss external competitiveness), would result in a higher probability of a regime change. We compute this variable using data on exchange rates and consumer price indices from the Bank of Spain (for the Spanish peseta) and IFS (lines 64), respectively.

In contrast with the First Generation models of currency crisis, Second Generation models emphasize the role of speculative proxies as potential causes of such crises. Following the empirical literature in this area, we examine the role of the following variables in explaining the probability of a regime change:

6. The interest rate differential with respect to Germany: Since this interest rate differential incorporates the anticipated differential in the inflation rates between both economies, an increase in this variable would indicate greater risk of devaluation, and therefore would generate expectations of future realignment, negatively affecting the duration of a given regime. In particular we use data on short-term interest rate (IFS, line 60c). 
7. A credibility measure: One would expect that growing credibility would be associated with significant reductions in the probability of a regime change. Following Ledesma-Rodríguez et al. (2001), we use the marginal credibility indicator $\delta_{t}$, defined as:

$$
s_{t}-E_{t-1}\left(s_{t}\right)=\gamma+\delta_{t}\left[c_{t}-E_{t-1}\left(s_{t}\right)\right]+u_{t}
$$

where $s_{t}$ is the logarithm of the exchange rate (expressed as the home currency price of a unit of foreign exchange), $c_{t}$ is the logarithm of the central parity, the expectation operator is conditional to the information available in $t-1$, and $u_{t}$ is a random disturbance. Note that different value of $\delta_{t}$ are obtained for each time period in the sample.

8. The central parity deviation: The higher the deviation from the central parity, the more difficult to defend it and, therefore, the higher the probability of a regime change.

The approach presented in Maroto-Illera et al. (2002) is of eclectic character. Its main advantage is that it allows one to examine which variables, representative of these currency-crisis models, are empirically relevant when evaluating the survival of the fixed parities within the EMS. Therefore, in an attempt to improve the explanatory power of these two approaches, the eclectic model combines the explanatory factors suggested by these two mainstreams.

\subsection{Political Explanatory Variables}

As far as political variables are concerned, the data come from The Comparative Political Data Set 1960-2001, by Armingeon et al. (2002). This is a collection of political and institutional statistics which covers a period of about 30 years and includes information on more than 20 countries. The political and institutional variables suggested by different Political Economy models, and whose effects in the functioning of the ERM we aim to investigate are:

1. Cabinet composition: As the Partisan Theory suggest, ideological differences between parties must be reflected in their attitudes towards the economy. Typically, left-wing parties care about unemployment and growth, while right-wing are more concerned with inflation. In order to explore the evidence for the case of the exchange rate policy, we will consider a variable that accounts for the ideological composition of the cabinet. This is a categorical variable taking values between one and five; the lower value in this scale (i.e. the one) corresponds to a situation of total hegemony of right-wing parties, while the upper (i.e. the five) represents the total hegemony of social-democratic and other left parties in the cabinet. However, the way in which this variable is defined may cause some problems when introduced into the empirical model. 
It is well-known that categorical variables require special attention in regression analysis because, unlike dichotomous or continuous variables, they cannot be entered into the regression equation just as they are. Categories may be unbalanced in the sense that distances between them are quite different. Regarding cabinet composition, we expect the ideological gap between centre and right-wing parties be shorter than that in the case of the left-wing parties; therefore, entering the original variable in the regression will look at the linear effect of the cabinet composition, which is not what we are interested in. To overcome this problem we recoded the original variable into a dummy, called $d m l e f t$, which will take the value one whenever left-wing parties have the hegemony in the cabinet (i.e. categories four and five in the original variable $)^{7}$. If left-wing parties are effectively more prone to depreciate, as the Partisian Theory predicts, we will expect a negative sign on the associated coefficient.

2. Elections: Politicians care about holding office (Alesina et al. 1997). Therefore, in order to maximize their re-election chances they are expected to (artificially) stimulate the economy in the run-up to an election. With respect to the exchange-rate policy, two contrary arguments may be used to hypothesize the influence on an imminent election. On the one hand, governments may use the exchange-rate to signal the reliability of their macroeconomic policies (Giavazzi and Pagano, 1988); in this case, policymakers will tend to delay depreciation until after the elections. On the other, it is the so-called "competitiveness" motive for depreciation; in countries where the tradable sector performs an outstanding role, a depreciation will boost the economy by making national goods more competitive both in world and home markets.

In the case of the ERM, the aims that inspired the inception of the system and its own architecture make the competitiveness argument very unlikely. Under a pegged exchange rate, policymakers have limited ability to affect the real exchange rate at will ${ }^{8}$. Moreover, realignments within the system needed the approval of all other participating currencies. Furthermore, both the EMS and her centrepiece, the ERM, constituted an important intermediary step to EMU (Sosvilla-Rivero and Pérez-Bermejo, 2003), an agreement to foster economic integration among European countries. Then, consistent with the "credibility-damaging" argument, we expect depreciations to be postponed after elections because of their inherent political costs.

To investigate this intuition we will include a dummy, electyear, taking

\footnotetext{
${ }^{7}$ Alternative characterizations, such as defining the variable in terms of the right-wing ideology, were also checked but the robustness of the results remained largely unaltered

${ }^{8}$ Nonetheless, policies may have an impact in the real exchange rate. Froot and Rogoff (1991) find that among EMS countries, government spending tends to fall heavily on nontraded goods what will have increased the real exchange rate. However, as Rogoff (1992) emphasizes, any such effect must be transitory
} 
the value one whenever an election occurred in the year in question ${ }^{9}$. If our ex-ante hypothesis were true, this variable should exhibit a negative sign.

3. Type of Government: Single party governments and multi-party temporarily coalitions are two extreme cases regarding government stability; between these two categories some intermediate figures, as minimal winning coalitions, surplus coalitions, single party minority governments or multiparty minority governments are feasible. The soundness of the macroeconomic policies implemented is expected to increase with the stability of the government, and this will translate into less frequent realignments as far as exchange rates are concerned. In order to investigate this intuition in the case of the ERM, we incorporate into the analysis a categorical variable that divides the type of governments (in terms of their stability) in six different categories.

In this scale, the lower values correspond to more stable governments (i.e. single party administration) while the higher are associated with more unstable administrations (i.e. multi-party temporarily governments). However, as in the case of the cabinet composition, the way in which this variable is defined may be potentially harmful for the empirical analysis. Again, the original classification postulates similar differences between categories, (i.e. it assumes a linear effect), what will mask the true effect of stability. To solve this shortcoming, we defined a dummy, dmtemporar$i l y$, which accounts for the most unstable category in the original scale (i.e. multi-party temporarily governments). If unstable governments effectively were associated with less consistent policies, the sign exhibited on this variable should be negative.

4. Central bank independence: Independent central banks are means of achieving credibility in policy making, thus reducing both the average of inflation and its variability (Alesina et al., 1997). As a low inflation facilitates the maintenance of a peg with a low-inflation anchor, like Germany in the case of the EMS, it may be expected a negative relation between the degree of central bank independence and the probability of a devaluation taking place.

The variable considered here is an index created by Freitag (1999) that compiles the information of some other measures [Alesina (1988), Cukierman (1992), Eijffinger and Haan (1996) and Grilli et al. (1991)] that have investigated different aspects of this "independence". For example the index constructed by Alesina (1988) analyses whether the central bank has final authority over monetary policy, while the index of Cukierman (1992) is more focused on some legal aspects. Hence, the main advantage of the

\footnotetext{
${ }^{9}$ We can adopt this definition since any of the eight countries under study experienced more than one electoral process in any particular year during the sample period considered
} 
index of we make use is precisely that summarizes several dimensions of "independence" into a single (continuous) variable.

\section{Empirical Results}

\subsection{A first look at the empirical hazard and survivor func- tions: The Non-Parametric approach}

As we discussed in the econometric section, a first way of analyzing the duration dependence of the data is to examine the empirical hazard and survivor functions. The Kaplan-Meier hazard estimate for the eight currencies under study is depicted in Figure 2. The great heterogeneity registered in the evolution of the ERM makes the pattern of the empirical hazard far from being conclusive; upand down-ward trends mix in a very irregular pattern reflecting not only differences in the conditions of the participating currencies but also some relevant changes in the functioning of the system itself. Only from the tenth quarter on we may infer negative duration dependence, though it should be noted that the accuracy of the estimator decreases as time passes since inferences about long durations are based on fewer observations.

Figure 2: Kaplan-Meier empirical hazard estimate

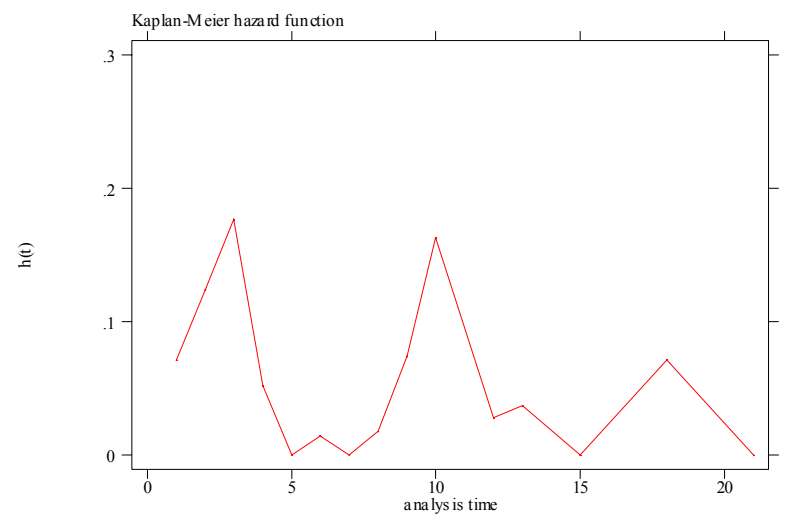

The Kaplan-Meier estimator for the survivor function is shown in Figure 3. As can be seen, the probability decreases sharply for durations of less than 4 quarters; for intermediate durations, among 4 and 10 quarters, the fall is smoother but also noticeable. Finally, for durations longer than 10 quarters this probability remains almost stable up its maximum (21 quarters). This behaviour suggests two different patterns in the evolution of the ERM: for those regimes with higher durations (more than 10 quarters) the ERM would have been stable, 
while for the regimes associated with lower durations (less than 4 quarters) the ERM would have been more unstable.

Figure 3: Kaplan-Meier survivor function

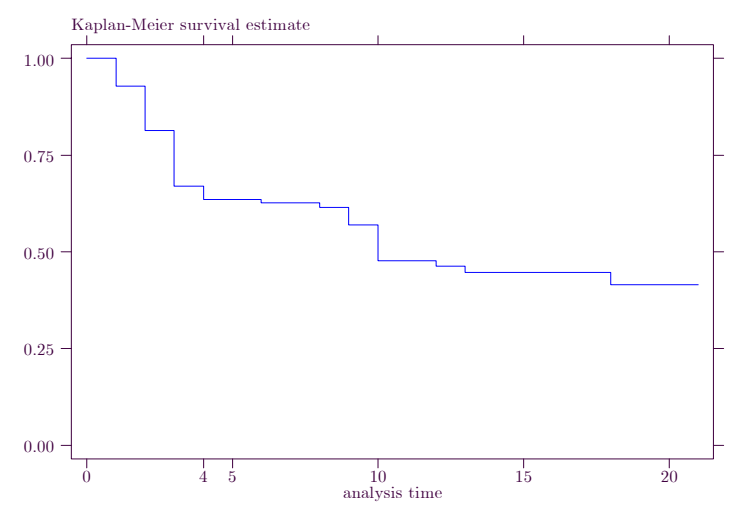

As a conclusion, the empirical approximation to the analysis of duration highlights the enormous variability present in the evolution of the ERM; striking differences between participating currencies, across different periods and in the functioning of the system itself enhance the need for incorporating additional variables into the analysis.

\subsection{Evaluating the role of economic and political factors: The Parametric approach}

Since the major contribution of this paper is the evaluation of some relevant political economy factors on the analysis of the ERM experience, and in the line with previous works (see Bussière and Mulder, 1999; Mulder et al., 2002), a useful starting point is to consider a benchmark model that provides a sufficiently clear picture of the role played by pure economic factors. The eclectic model developed in our previous work (see Maroto-Illera et al.,2002) will be used as the reference for convincing reasons:

- It combines a wide range of economic variables suggested by the two predominant strands in the currency crisis literature: First and Second Generation models. Furthermore, the findings obtained are closely related to those of some other papers focused on the analysis of the EMS experience [see Eichengreen, Rose y Wyplosz (1995) and Ötker y Pazarbasioglu (1997)]

- It considers the same group of countries and it is estimated in the same sample period that we consider here, thus permitting the comparability of the results. 
- The eclectic specification outperforms both in terms of explanatory power (AIC criterion) and goodness of fit (Cox-Snell residuals), the specifications that separately consider economic fundamentals, on the one hand, and proxies of speculative pressures, on the other

- The model is also estimated using duration analysis. The results obtained in Maroto-Illera et al (2002) are consistent with that obtained using alternative estimation procedures (i.e., probit/logit models)

- Finally, , the eclectic economic model can be seen as a first step in the analysis in which our main concern is to look for the economic factors that might have determined the exchange rate policies in the EMS. The results in Maroto-Illera et al (2002) provide evidence that the model is not misspecified, so we can try to answer the question: have political variables something to say when the relevant economic factors are properly controlled?

Table 2 summarises the results for the eclectic specification. Before turning to the analysis of the Political Economy factors and given that this model will be used as the starting point, it is valuable to discuss their main predictions.

Table 2: Parametric estimation of the Eclectic Model

\begin{tabular}{|c|c|c|c|c|}
\hline Variables & $\begin{array}{l}\text { Exp. } \\
\text { Sign }\end{array}$ & $\mathrm{COX}$ & WEIBULL & EXPONENTIAL \\
\hline Reserves & - & $\begin{array}{l}-0.400 \\
(3.13)^{* *}\end{array}$ & $\begin{array}{l}-0.608 \\
(4.43)^{* *}\end{array}$ & $\begin{array}{l}-0.411 \\
(-2.63)^{*}\end{array}$ \\
\hline Real ER & + & $\begin{array}{l}0.010 \\
(3.13)^{* *}\end{array}$ & $\begin{array}{l}0.014 \\
(4.40)^{* *}\end{array}$ & $\begin{array}{l}0.010 \\
(2.66)^{* *}\end{array}$ \\
\hline Price Index ${ }^{G}$ & - & $\begin{array}{l}-5.134 \\
(2.69)^{* *}\end{array}$ & $\begin{array}{l}-5.402 \\
(2.52)^{* *}\end{array}$ & $\begin{array}{l}-4.428 \\
(2.77)^{* *}\end{array}$ \\
\hline $\mathrm{i}-\mathrm{i}^{\mathrm{G}}$ & + & $\begin{array}{l}0.187 \\
(2.34)^{* *}\end{array}$ & $\begin{array}{l}0.257 \\
(2.46)^{* *}\end{array}$ & $\begin{array}{l}0.201 \\
(2.55)^{* *}\end{array}$ \\
\hline Credibility & - & $\begin{array}{c}-0.992 \\
(1.85)^{*}\end{array}$ & $\begin{array}{l}-1.315 \\
(2.11)^{* *}\end{array}$ & $\begin{array}{c}-1.124 \\
(1.94)^{*}\end{array}$ \\
\hline Desv CP & + & $\begin{array}{l}0.004 \\
(3.26)^{* *}\end{array}$ & $\begin{array}{l}0.006 \\
(4.15)^{* *}\end{array}$ & $\begin{array}{l}0.004 \\
(2.84)^{* *}\end{array}$ \\
\hline Constant & & & $\begin{array}{l}0.866 \\
(0.42)\end{array}$ & $\begin{array}{l}1.087 \\
(0.73)\end{array}$ \\
\hline Theta & & & $\begin{array}{l}1.479 \\
(9.60)^{* *}\end{array}$ & \\
\hline AIC & & 520.76 & 252.04 & 263.36 \\
\hline \multicolumn{5}{|c|}{$\begin{array}{l}\text { Absolute z-statistics in parentheses } \\
\text { Standard errors adjusted for clustering on currency } \\
\text { * significant at } 10 \% ; * * \text { significant at } 5 \% \\
{ }^{G} \text { refers to Germany }\end{array}$} \\
\hline
\end{tabular}

As this table shows, all the coefficients are significant at the usual level and show the expected sign. More in detail, the level of international reserves, the 
level of prices in Germany and the credibility measure (see Ledesma-Rodríguez et al., 2001) have a negative effect on the probability of a realignment occurring. On the contrary, the real exchange rate, the (short-term) interest rate differentials with Germany and the deviations around the central parity will positively affect the probability of change.

These results are closely connected with the predictions of First and Second Generation models of currency crises. As the first type of models suggest, under a fixed regimen, the persistence of weak economic fundamentals over time - represented in our specification by a low level of reserves, an overvalued real exchange rate and high inflation differentials with respect to the anchor of the system - will inevitably result in the abandon of the fixed rate. Second generation models, in contrast, relates the collapse of the system with market expectations; market feelings are underlay in some variables — picked by high interest rate differentials, a noticeable deviation from the central parity and a low credibility - that put additional pressures on the currency and may cause its collapse. As a conclusion, these results demonstrate that the sustainability of a given exchange rate regime in the ERM was influenced by both fundamental variables and some proxies of the animal spirits Furthermore, this evidence is indicative that the implementation of sound economic policies is a necessary but not a sufficient perquisite to prevent a devaluation; policymakers must also strength their reputational capital to convince the markets.

After discussing our benchmark model, we now turn to the incorporation of the political and institutional factors previously commented. Following the methodology used in the estimation of the eclectic model and given that the function for the baseline hazard determines the parametric model to be estimated, we propose three different models: Cox, Weibull and Exponential. In order to obtain the empirical specification that best fits the data we will follow a "General-to-Specific" modelling strategy; starting from the most general specification (i.e. the one that combines the economic variables of the eclectic model together with the political and institutional factors), we progressively simplify and re-parameterise the model until a parsimonious representation of the data generating process was arrived at (Hendry, 1995).

Table 3 summarizes the estimation results of the model that mixes the economic and political variables; all the coefficients included are significant at the usual level and most of them show the expected sign. As can be seen, the coefficients and significance for the economic variables of our eclectic model remain largely stable, providing additional robustness to that model. 
Furthermore, all of the parameters in Table 2 are within the $95 \%$ confidence interval that we have estimated in Table 3, except for the level of international reserves and the real exchange rate in the Weibull specification. This result can be interpreted as suggesting that, even though the policy variables do influence the probability of a realignment inside the ERM, there is no significant change in the influence of the economic variables on this probability.

Table 3: Estimation results

\begin{tabular}{|c|c|c|c|c|}
\hline Variables & $\begin{array}{l}\text { Exp. } \\
\text { Sign }\end{array}$ & $\operatorname{COX}$ & WEIBULL & EXPONENTIAL \\
\hline Reserves & - & $\begin{array}{c}-0.579 * * \\
(4.61)\end{array}$ & $\begin{array}{c}-1.051^{* *} \\
(5.89)\end{array}$ & $\begin{array}{c}-0.462^{* * *} \\
(8.33)\end{array}$ \\
\hline Real ER & + & $\begin{array}{c}0.017^{* * *} \\
(3.21)\end{array}$ & $\begin{array}{c}0.028^{* *} \\
(4.33)\end{array}$ & $\begin{array}{c}0.014 * * \\
(4.74)\end{array}$ \\
\hline Price Index ${ }^{G}$ & - & $\begin{array}{c}-7.949 * * \\
(3.12)\end{array}$ & $\begin{array}{c}-9.730^{* *} \\
(3.13)\end{array}$ & $\begin{array}{c}-5.927^{* * *} \\
(3.62)\end{array}$ \\
\hline$\left(\mathrm{i}-\mathrm{i}^{\mathrm{G}}\right)$ & + & $\begin{array}{c}0.191 * * \\
(4.32)\end{array}$ & $\begin{array}{l}0.271^{* *} \\
(4.87)\end{array}$ & $\begin{array}{c}0.201 \text { ** } \\
(4.31)\end{array}$ \\
\hline Credibility & - & $\begin{array}{c}-0.868^{* *} \\
(2.38)\end{array}$ & $\begin{array}{c}-1.355^{* *} \\
(2.89)\end{array}$ & $\begin{array}{c}-0.895^{*} \\
(1.76)\end{array}$ \\
\hline Dev. Central Parity & + & $\begin{array}{c}0.007 \text { ** } \\
(3.28)\end{array}$ & $\begin{array}{l}0.011 * * \\
(4.37)\end{array}$ & $\begin{array}{c}0.006 * * \\
(4.68)\end{array}$ \\
\hline Gov. Left & + & $\begin{array}{r}-0.177 \\
(0.77)\end{array}$ & $\begin{array}{c}-0.368^{*} \\
(1.91)\end{array}$ & $\begin{array}{c}-0.316^{*} \\
(1.95)\end{array}$ \\
\hline Temporarily Gov. & + & $\begin{array}{c}2.005 * * \\
(4.56)\end{array}$ & $\begin{array}{l}2.804^{* *} \\
(4.10)\end{array}$ & $\begin{array}{l}1.540^{* * *} \\
(3.48)\end{array}$ \\
\hline Electoral Year & - & $\begin{array}{c}-0.505^{* *} \\
(2.09)\end{array}$ & $\begin{array}{c}-0.859^{* *} \\
(3.07)\end{array}$ & $\begin{array}{c}-0.450^{* * *} \\
(2.84)\end{array}$ \\
\hline Central Bank Ind. & - & $\begin{array}{c}-0.478^{* *} \\
(2.96)\end{array}$ & $\begin{array}{c}-0.655^{* *} \\
(2.65)\end{array}$ & $\begin{array}{c}-0.431^{* * *} \\
(2.28)\end{array}$ \\
\hline Constant & & - & $\begin{array}{l}5.338 * * \\
(2.11)\end{array}$ & $\begin{array}{c}3.323 * * \\
(2.30)\end{array}$ \\
\hline Theta & & - & $\begin{array}{c}1.879 \text { ** } \\
(8.58)\end{array}$ & - \\
\hline AIC & & 402.62 & 188.58 & 213.51 \\
\hline $\begin{array}{l}\text { Absolute z-statistics in } \\
\text { Standard errors adjuste } \\
\left({ }^{*}\right) \text { significant at the } 10 \\
{ }^{\circ} \text { refers to Germany }\end{array}$ & 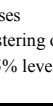 & & & \\
\hline
\end{tabular}

Given the noisy picture exhibited by the empirical hazard (see figure 2), an interesting hypothesis to test for the presence of duration dependence, once we control (part of) the heterogeneity present in the data, is to conduct a test regarding the ancillary parameter in the Weibull model. Recall from equation (3) that if $\theta$ were greater (lower) than one, the duration dependence would be positive (negative) while if it were equal to unity the Weibull distribution would collapse to the Exponential, suggesting no duration dependence. As it is shown in table 3 , the point estimate of the parameter is 1.88 , suggesting positive duration dependence; additionally, the test for the null $\theta=1$ (i.e. no duration dependence) is rejected at the $1 \%$ level. We may conclude that, conditional on the economic and political factors included, the data exhibit positive duration dependence, indicating that (other things equal) the probability of a regime change increases over time. This result strengthens the use of duration models.

Concerning the interpretation of the political variables investigated, the results indicate that in the ERM experience left-wing governments, electoral years 
and independent central banks would have negatively affected the probability of a regime change, while less stable governments would have been more prone to realign the central parities. These relations largely agree with the main implications of the Political Economy models previously commented. Only the negative sign associated with the dummy representing left-wing governments would contradict the standard prediction of the Partisan theory. Nevertheless, it may be consistent with the importance of the use of the exchange rate as a nominal anchor for credibility-enhancing purposes, signalling the commitment to stable policies desired by the market participants. Moreover, this positive association between left-wing government and regimen stability would be in line with the changes registered in the political agendas all over Europe as results of the EMU. For example, Mélitz (1995) argued that "[T]he French behaviour can be best explained on the basis of long-run political goals. By maintaining the policy of the franc fort, the French authorities wished to promote the aim of Monetary Union" (Mélitz, 1995, p. 26). In the same line, Drazen and Masson (1994) showed how "la politique de rigueur" implemented by Mitterand's first socialist government, enhanced the credibility for a "hard currency peg" policy, even at a cost of a higher unemployment. The commitment to a strong franc convinced investors that the priorities of the authorities had changed, what was reflected in a shorten of (long-term) interest rate differentials with Germany. Finally, this finding is also consistent with the results in Frieden (2002), whose analysis of the EMS shows how left-wing governments were associated with less volatile currencies, and Leblang (2002), who argues that left governments are more likely to use all policy tools at their disposal to prevent a speculative attack in the run up to an election.

In spite of the evidence supporting the sign on the dmleft coefficient for the case of the EMS, we have performed a further test. Figure 4 graphs the Kaplan-Meier survivor function for those countries with a predominance of leftwing parties in their administrations during the period analyzed. As this figure reveals, the survivor function corresponding to those countries with a large number of socialist administrations (i.e. France, Denmark and Spain) is most of the time above of that associated with more right-wing oriented. Then, in the EMS light, countries with a predominance of left-wing administrations would have been associated with more stable exchange rate regimens than those more conservative prone. 
Figure 4: Kaplan-Meier survivor function: Left- Vs Right-wing prone countries

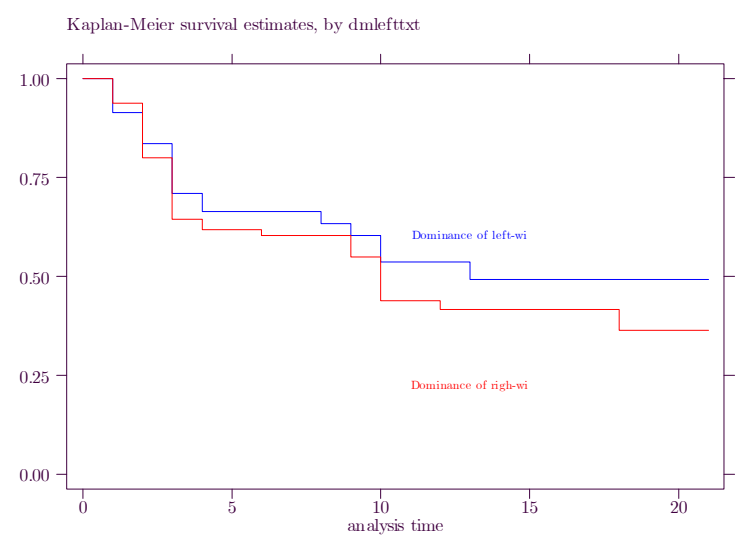

\subsection{Assessing the goodness of fit}

After carrying out the estimation, a natural question to ask is which of the three parametric models (i.e., Cox, Weibull and Exponential) is the best in terms of goodness of it. To discriminate among them we have employed two different criteria widely used in the duration analysis literature: the Akaike Information Criterion (AIC) and the Cox-Snell residuals.

The AIC is particularly suitable for comparing models that are not nested. Akaike (1974) proposed penalizing each log likelihood to reflect the number of parameters being estimated in a particular model and then comparing them, choosing the one with the lowest AIC statistic. In our case, as table 3 shows, the Weibull model exhibits the lower AIC and so, according to this criterion, should be the preferred.

A second way to assess the goodness of fit of the three parametric models is to look at their Cox-Snell residuals (Cox and Snell, 1968). These residuals are defined as follows:

$$
\widehat{e}=-\log S(t \mid X)
$$

where $S(t \mid X)$ is the estimated probability of surviving to time t. Then, if the model fits the data, these residuals should have a standard censored exponential distribution with hazard ratio equal to one (Cox, 1972). We can verify this intuition simply by plotting an empirical estimate of the cumulative hazard, taking the Cox-Snell residuals as the time variable, versus these residuals themselves. This plot should be a straight line with slope equal to one. As figure 5 clearly shows, the Weibull model is the one with the lowest departures form the $45^{\circ}$ reference line, indicating also the best fit in terms of this second criterion. 
Figure 5: Cox-Snell residuals
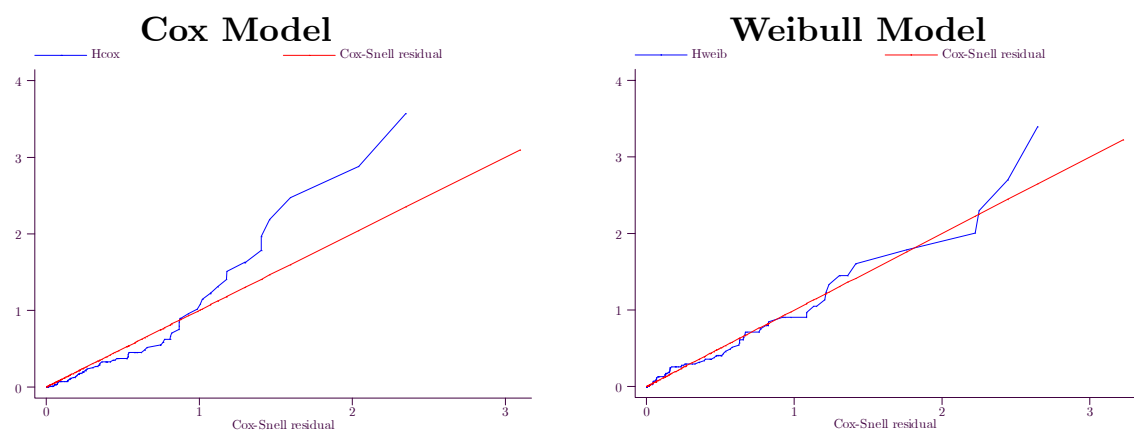

\section{Exponential Model}

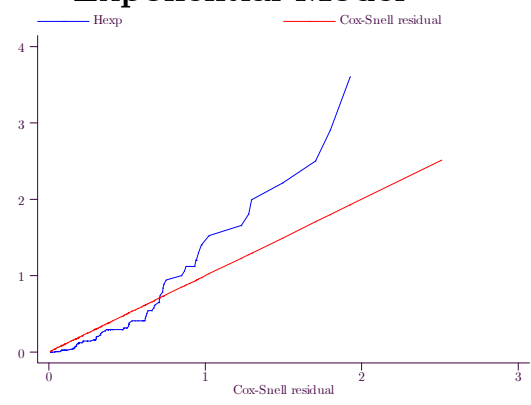

As a conclusion, the two criteria presented here yield conclusive evidence in favour of the Weibull model as that exhibiting the superior fit. This result agrees with that obtained in Maroto-Illera et al (2002) regarding the (economic) eclectic model.

Perhaps a more interesting question is to compare the political augmented model with our eclectic benchmark both in terms of explanatory power and goodness of fit. Recall that both the AIC and the Cox-Snell residuals are still two valid criteria to perform the comparison. First, in terms of explanatory power, the AIC statistic for the political model is lower than that for the reference one (i.e. 188.58 versus 252.04 ), indicating an improvement in the explanatory power of the original model. Moreover, note that for the other two specifications (i.e. Cox and Exponential) the AIC for the augmented model is always lower than the benchmark, suggesting that the addition of the political variables helps to improve explanatory power.

Regarding the goodness of fit, figure 6 depicts the Cox-Snell residuals for both the Weibull political augmented and benchmark specifications ${ }^{10}$. As can be

\footnotetext{
${ }^{10}$ For the economy of space we have omitted the figures for the Cox and Exponential models (available upon request). Again, in these two cases the political augmented model exhibits a superior fit
} 
seen, the residuals for the first model show fewer departures from the reference line than the benchmark. Hence, according to this figure, we could assert that the fit of the political model outperforms that of the reference specification.

Figure 6: Cox-Snell residuals; Political Vs Benckmark models

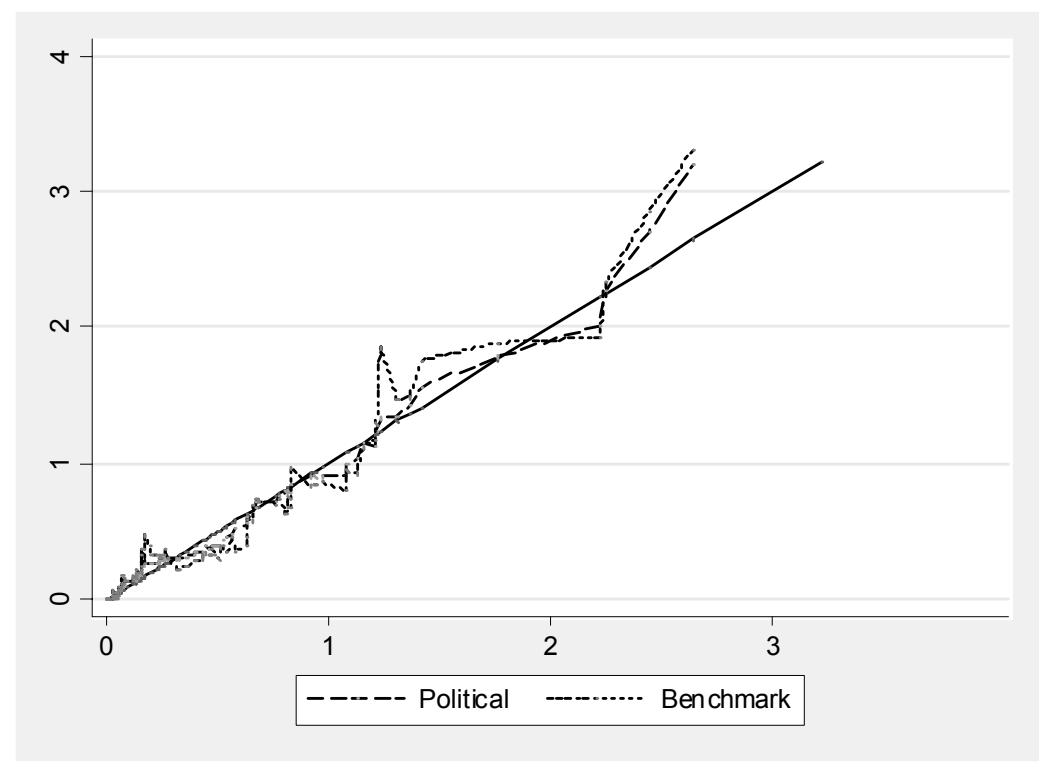

\subsection{Unobserved Heterogeneity}

Parametric specification plus covariates can only go to a certain point in accounting for the variability in observed durations. In duration models this overdispersion, which the model is unable to explain, is introduced by means of a multiplicative factor $\vartheta$, the frailty, which scales both the hazard and survivor functions. More precisely, in the PH framework the effect of this latent variable is modelled according to:

$$
h_{\vartheta}(t) \equiv h(t, X \mid \vartheta)=h_{0}(t) \exp \left(X^{\prime} \beta\right) \vartheta
$$

Two key assumptions used in most models that incorporate unobserved heterogeneity are: (a) the heterogeneity must be independent of the observed covariates; (b) the heterogeneity term follows a known finite distribution supported on the positive numbers. The latent factor, $\vartheta$, in (4) may be interpreted in several ways. The most common one is that it summarizes the impact of omitted covariates on the hazard rate; when applied to our analysis, we may think in this term as capturing idiosyncratic factors (neither of economic nor of political character, given the strict exogeneity assumption expressed in (a)) that affected the evolution of our sample of currencies. 
Given the multiple-spell structure of the data (i.e. each currency experiences more than one change) we must be careful when dealing with the introduction of the unobserved heterogeneity in our model. In particular, we must assume that each realization of the random variable is common to all the observations for each currency ${ }^{11}$.

The estimation of an unobserved heterogeneity model is also useful in evaluating the robustness of our previous results. Recent works have suggested some potential bias in which we may incur when ignoring the frailty term. On one hand, the non-frailty model seems to over-estimate the degree of negative duration dependence in the (true) baseline hazard, and under-estimate the degree of positive duration dependence (Wooldridge, 2002). Moreover, the estimate of a positive (negative) $\beta_{k}$ (i.e. the effect of regressor $X_{k}$ on the hazard rate) derived from the non-frailty model would under-estimate (over-estimate) the true parameter (Lancaster, 1990). Therefore, comparing the estimations from the model that incorporates unobserved heterogeneity with that obtained from the non-frailty model will provide a useful insight about how harmful are the covariates that we are omitting.

Estimating the frailty model requires an explicit assumption about the functional form of the density of $\vartheta$. As expressed in assumption (b), any continuous distribution with positive support and finite variance will be valid; however the literature about this question usually restricts the election to either the Gamma or the Inverse-Gaussian distributions. For the PH models, the Gamma with normalized mean to one and finite variance $\sigma^{2}$ has been the most popular.

In table 4 we compare the estimations of the non-frailty Weibull model, the one with the best fit, and the frailty model, assuming that $\vartheta$ follows a Gamma $\left(1 / \sigma^{2}, \sigma^{2}\right)$ distribution ${ }^{12}$.

\footnotetext{
${ }^{11}$ This way of treating the unobserved heterogeneity is known as shared frailty and is incorporated in the statistical package STATA 8.1

${ }^{12}$ We also estimated the frailty model assuming that $\vartheta$ followed a Inverse Gaussian $\left(1,1 / \sigma^{2}\right)$ and the estimates remain unaltered. Hence, our result look quite robust to the choice of the distribution for the unobserved heterogeneity
} 
Table 4: Non-frailty Vs Frailty models

\begin{tabular}{|c|c|c|}
\hline Variables & $\begin{array}{c}\text { Reference } \\
\text { Model }\end{array}$ & $\begin{array}{l}\text { Frailty } \\
\text { Model }\end{array}$ \\
\hline Reserves & $\begin{array}{c}-1.051^{* *} \\
(5.89)\end{array}$ & $\begin{array}{c}-1.051^{* *} \\
(2.06)\end{array}$ \\
\hline Real ER & $\begin{array}{c}0.028^{* *} \\
(4.33)\end{array}$ & $\begin{array}{c}0.028^{* *} \\
(2.43)\end{array}$ \\
\hline Price Index ${ }^{G}$ & $\begin{array}{c}-9.730 * * \\
(3.13)\end{array}$ & $\begin{array}{c}-9.730 * * \\
(4.27)\end{array}$ \\
\hline$\left(i-i^{G}\right)$ & $\begin{array}{c}0.271 * * \\
(4.87)\end{array}$ & $\begin{array}{c}0.271^{* *} \\
(4.65)\end{array}$ \\
\hline Credibility & $\begin{array}{c}-1.355^{* *} \\
(2.89)\end{array}$ & $\begin{array}{c}-1.349 * * \\
(2.66)\end{array}$ \\
\hline Dev. Central Parity & $\begin{array}{c}0.011^{* *} \\
(4.37)\end{array}$ & $\begin{array}{c}0.011^{* *} \\
(2.45)\end{array}$ \\
\hline Gov. Left & $\begin{array}{c}-0.368^{*} \\
(1.91)\end{array}$ & $\begin{array}{r}-0.368^{*} \\
(1.91)\end{array}$ \\
\hline Temporarily Gov. & $\begin{array}{c}2.804 * * \\
(4.10)\end{array}$ & $\begin{array}{c}2.804^{* *} \\
(3.07)\end{array}$ \\
\hline Electoral Year & $\begin{array}{c}-0.859^{* *} \\
(3.07)\end{array}$ & $\begin{array}{c}-0.859^{* *} \\
(2.52)\end{array}$ \\
\hline Central Bank Ind. & $\begin{array}{c}-0.655^{* *} \\
(2.65)\end{array}$ & $\begin{array}{c}-0.655 * * \\
(2.09)\end{array}$ \\
\hline Constant & $\begin{array}{c}5.338 * * \\
(2.11)\end{array}$ & $\begin{array}{c}5.339 * * \\
(2.68)\end{array}$ \\
\hline Theta & $\begin{array}{c}1.879^{* *} \\
(8.58)\end{array}$ & $\begin{array}{c}1.879 * * \\
(9.35)\end{array}$ \\
\hline $\mathrm{AIC}$ & 188.58 & 191.32 \\
\hline $\begin{array}{l}\text { Absolute } z \text {-statistics in } \\
\text { Standard errors adjuste } \\
(*) \text { significant at the } 10\end{array}$ & $\begin{array}{l}\text { theses } \\
\text { clustering on } \\
* \text { ) } 5 \% \text { levels }\end{array}$ & ency \\
\hline
\end{tabular}

These result yield strong support to our previous estimates as long as all the coefficients remain almost identical; moreover, the point estimate for $\theta$, the parameter which measures the duration dependence, is unaltered. Hence, the omitted variables look of little importance in explaining the regime changes observed within the ERM.

After the model has been estimated, a final assessment regarding the relevance of the frailty term is to perform a test for the null hypothesis $\sigma^{2}=0$. If the null were rejected this would be additional evidence against the inclusion of the common latent effect $\vartheta$. Table 5 presents the results of the likelihood-ratio test for this hypothesis. The null can not be rejected at the $1 \%$ level, indicating that we may ignore the frailty term for estimation purposes.

Table 5: Likelihood-ratio (LR) Test

$$
\begin{gathered}
H_{0}: \sigma^{2}=0 \\
\chi_{1}^{2}=0.00 \\
\text { Prob } \geq \chi_{1}^{2}=1.00
\end{gathered}
$$




\section{Concluding Remarks}

This paper has attempted to expand the scarce research available on the role of political variables in explaining currency crises by focusing on the EMS experience. Since market participants incorporate information from a variety of sources into their expectations, we think that political variables may play a significant role in explaining currency developments. Therefore, we have applied an eclectic approach, that enables us to explicitly incorporate political and institutional factors into the explanation of exchange rate policies, in contrast to almost all existing analyses that have focused entirely on economic factors.

Our results indicate that both economic and political factors are important determinants of European currency policy. Considering just pure economic factors, the real exchange rate, interest differentials and central parity deviations would have negatively affected the duration of a given regime, while credibility, the level of international reserves and the price level in the anchor country would have positively influenced this duration. Regarding political factors, elections, central bank independence and left-wing government increase the probability of maintaining the current regime, while less stable governments would be associated with a regimen change.

The study provides several implications for macroeconomic policy. It reveals that the sustainability of a given regime in the ERM discipline was affected both by fundamental variables and by investor's expectations about government behaviour. Such a result might indicate that to prevent currency crises it is not sufficient to pursue sound economic policies, but policymakers must enhance their reputational capital with respect to their commitment to maintain the exchange rate around the central parity.

The findings also shed light on the role of policy variables during the EMS history through the expectations generated by the market. Our results suggest that unstable governments associated with less consistent policies would have been more prone to devaluate. In addition, we find a negative relation between the degree of central bank independence and the probability of a devaluation taking place, indicating that an independent central bank would have been able to stabilise the exchange rate more freely than a dependent one. Moreover, consistently with the opportunistic models, electoral years would have negatively affected the probability of a regimen change, suggesting that realignments would have been postponed after elections because of their inherent political costs. Finally, in contrast to partisan models, left-wing governments would have positively influenced the duration of a given central parity. Nevertheless, this result may be consistent with the importance of the use of the exchange rate as a nominal anchor for credibility-enhancing purposes. Since left-wing governments had questionable credibility so far as price stability is concerned, they will be more likely to use all policy tools at their disposal to stabilise the economy, and therefore realignments would have been less likely when this government are in power.

Finally, we have shown how the political augmented model outperforms, both in terms of explanatory power and goodness of fit, our benchmark (eco- 
nomic) model, supporting the implications of previous papers (Mélitz, 1999; Bussière and Mulder, 1999) which emphasized the improvement in the results when political and institutional variables were incorporated into the analysis of currency crises.

The eclectic approach used here is very informative and could be applied for studying currency crisis in other countries. This extension will be the subject of the next research of the authors. 


\section{References}

[1] Akaike, H. (1974): "A New Look at the Statistical Model Identification", IEEE Transactions on Automatic Control AC, 19: 716-723.

[2] Alesina, A. (1987): "Macroeconomic Policy in a Two-Party System as a Repeated Game", Quarterly Journal of Economics 102: 651-678.

[3] Alesina, A. (1988): Macroeconomics and Politics, in O. Blanchard and S. Fischer (eds.), NBER Macroeconomics Annual. Cambridge, MA.: The MIT Press.

[4] Alesina, A., Roubini, N. and Cohen, G. D. (1997): Political Cycles and the Macroeconomy. Cambridge, MA.: The MIT Press.

[5] Armingeon, K., Beyeler, M. and Menegale, S. (2002): Comparative Political Data Set 1960-2001. Institute of Political Science, University of Berne.

[6] Bajo-Rubio, O., Sosvilla-Rivero, S. y Fernández-Rodríguez, F. (2001): "Asymmetry in the EMS: New Evidence Based on Non-linear Forecasts", European Economic Review 45: 451-473.

[7] Blanco, H. and Garber, P. (1986): "Recurrent Devaluation and Speculative Attacks on the Mexican Peso", Journal of Political Economy 94: 148-166.

[8] Bover, O., Arellano, M. and Bentolila, S. (1997): "Unemployment Duration, Benefit Duration and the Business Cycle", The Economic Journal 112: $223-265$.

[9] Bussière, M. and Mulder, C. (1999): "Political Instability and Economic Vulnerability", IMF Working Paper 99/46, IMF.

[10] Cox, D. R. (1972): "Regression Models and Life Tables", Journal of the Royal Statistical Society B34: 187-202.

[11] Cox, D. R. and Snell, E. J. (1968): "A General Definition of Residuals (with Discussion)", Journal of the Royal Statistical Society B39: 248-275.

[12] Cukierman, A. (1992): Central Bank Strategy, Credibility and Independence: Theory and Evidence. Cambridge, MA.: The MIT Press.

[13] Drazen, A. and Masson, P. (1994): "Credibility of Policies Versus Credibility of Policymakers", Quarterly Journal of Economics 109: 735-754.

[14] Eichengreen, B.; Rose, A. and Wyplosz, C. (1995): "Exchange Market Mayhem: The Antecedents and Aftermath of Speculative Attacks", Economic Policy 21: 249-312.

[15] Eijffinger, S. and De Haan, J. (1996): "The Political Economy of CentralBank Independence", Princeton Studies in International Economics 19, Princeton University. 
[16] Freitag, M. (1999): "Politik und Währung. Ein internationaler Vergleich". PhD Dissertation. University of Bern.

[17] Frieden, J. A. (2002): "Real sources of European currency policy: Sectoral interests and European monetary integration", International Organization 56: $831-860$

[18] Froot, K. and Rogoff, K. (1991): The EMS, the EMU, and the Transition to a Common Currency in O. Blanchard and S. Fischer (eds.), NBER Macroeconomics Annual. Cambridge, MA.: The MIT Press.

[19] Giavazzi, F. and Pagano, M. (1988): "The Advantage of Tying One's Hands: EMS Discipline and Central Bank Credibility", European Economic Review 32: 1055-1082.

[20] Grilli, V.; Masciandaro, and Tabellini (1991): "Political and Monetary Institutions and Public Financial Policies in the Industrial Countries", Economic Policy 13: 341-392.

[21] Hendry, D. F. (1995): Dynamic Econometrics. Oxford: Oxford University Press.

[22] Hibbs, D. (1977): "Political parties and Macroeconomic Policies", American Political Science Review 71: 1467-1487.

[23] Kaplan, E.L. and Meier, P. (1958). "Nonparametric Estimation from Incomplete Observations", Journal of American Statistic Association 53: 457-481.

[24] Krugman, P. (1979) : "A Model of Balance-of-payments Crises", Journal of Money, Credit and Banking 11: 311-325.

[25] Lancaster, T. (1990): The Econometric Analysis of Transition Data. Cambridge: Cambridge University Press.

[26] Leblang, David A. (2002): "The Political Economy of Speculative Attacks in the Developing World", International Studies Quarterly 46: 69-91.

[27] Ledesma-Rodríguez, F., Navarro-Ibáñez, M, Pérez-Rodríguez, J. and Sosvilla-Rivero, S. (2001): "Assessing the Credibility of a Target Zone: Evidence from the EMS", Working Paper 2001-04, FEDEA.

[28] Lindbeck, A. (1976): "Stabilization Policies in Open Economies with Endogenous Politicians", American Economic Review (Papers and Proceedings) 66: 1-19.

[29] Maroto-Illera, R., Pérez-Bermejo, F. and Sosvilla-Rivero, S. (2002): "An Eclectic Approach to Currency Crises: Drawing Lessons from the EMS Experience", Working Paper 2002-22, FEDEA. 
[30] McCloughan, P. y Stone, I. (1998): "Life Duration of Foreign Multinational Subsidiaries: Evidence from UK Northern Manufacturing Industry 197093", International Journal of Industrial Organization 16: 719-747.

[31] Mélitz, J. (1994): French Monetary Policy and Recent Speculative Attacks on the Franc, in D. Cobham (ed.), European Monetary Upheavals. Manchester: Manchester University Press.

[32] Mélitz, J. (1995): "Comment" in C. Bordes, E. Giardin and J. Mélitz (eds.): European Currency Crises and After. Manchester: Manchester University Press.

[33] Mulder, C.; Perrelli, R. and Rocha, M. (2002): "The Role of Corporate, Legal and Macroeconomic Balance Sheet Indicators in Crisis Detection and Prevention", IMF Working Paper 02/59, IMF.

[34] Nordhaus, W. (1975): "The Political Business Cycle", Review of Economic Studies 42: 169-190.

[35] Obstfeld, M. (1994): "The Logic of Currency Crises", Working Paper 4640, NBER.

[36] Ötker, I. and Pazarbasioglu, C. (1997): "Speculative Attacks and Macroeconomic Fundamentals: Evidence from Some European Countries", European Economic Review 41: 847-860.

[37] Persson, T. and Tabellini, G. (1990): Macroeconomics Policy, Credibility and Politics. Chur, Switerzland: Harwood Academic Publishers.

[38] Rogoff, K. (1985): "The Optimal Degree of Commitment to an Intermediary Monetary Target", Quarterly Journal of Economics 100: 1169-1190.

[39] Rogoff, K. and Sibert, A. (1988): "Elections and Macroeconomics Policy Cycles". Review of Economic Studies 55: 1-16.

[40] Rogoff, K. (1990): "Equilibrium Political Budget Cycles", American Economic Review, 80, pp. 21-36.

[41] Rogoff, K. (1992): "Traded Goods Consumption Smoothing and the Random Walk Behavior of the Real Exchange Rate", Bank of Japan Monetary and Economic Studies 10: 1-29.

[42] Roubini, N.and Sachs, J. (1989): "Political and Economic Determinants of Budget Deficits in the Industrial Democracies", European Economic Review 33(5): pp. 903-933.

[43] Sosvilla-Rivero, S. and Pérez-Bermejo, F. (2003): "Credibility and Duration in Target Zones: Evidence from the EMS". forthcoming in Progress in Economic Research: Special Issue on International Macroeconomics.

[44] Wooldridge, J.M. (2002): Econometric Analysis of Cross Section and Panel Data, Massachusetts: The MIT Press. 


\section{RELACION DE DOCUMENTOS DE FEDEA}

\section{DOCUMENTOS DE TRABAJO}

2004-04: "Currency Crises and Political Factors: Drawing Lessons from the EMS Experience", Francisco Pérez-Bermejo y Simón Sosvilla-Rivero

2004-03: "El futuro de las pensiones en España: Perspectivas y lecciones", J. Ignacio Conde-Ruiz y Javier Alonso Meseguer.

2004-02: "Do temporary contracts increase work accidents? A microeconometric comparison between Italy and Spain", Virginia Hernanz y Luis Toharia.

2004-01: "Job Match Quality throughout the Business Cycle in the Spanish Labour Market", Cristina Fernández.

2003-30: "Innovation, Investment and Productivity: Evidence from Spanish Firms", Omar Licandro, Reyes Maroto y Luis A. Puch.

2003-29: "Efectos de las ayudas europeas sobre la economía madrileña, 1990-2006: Un análisis basado en el modelo Hermin", Simón Sosvilla-Rivero y José A. Herce.

2003-28: “Canarias y los Fondos Estructurales europeos", Simón Sosvilla-Rivero.

2003-27: “How Brand Names Affect the Price Setting of Carmakers Producing Twin Cars?", Nora Lado, Omar Licandro y Francisco Pérez-Bermejo.

2003-26: "La desigualdad salarial en España. Efectos de un diseño muestral complejo", Juan Ramón García López.

2003-25: "Sobre la efectividad de la política regional comunitaria: El caso de Castilla-la Mancha", Simón Sosvilla-Rivero, Oscar Bajo Rubio y Carmen Díaz Roldán.

2003-24: "El diseño complejo de la Encuesta de Estructura Salarial 1995: Implicaciones sobre la estimación de medidas de desigualdad", Juan Ramón García López.

2003-23: "Polarization, Inequality and Tax Reforms", Juan Prieto, Juan Gabriel Rodríguez y Rafael Salas.

2003-22: “El efecto del capital humano sobre el crecimiento: ¿ Importa el periodo muestral?”, Simón Sosvilla-Rivero y Javier Alonso Meseguer.

2003-21: "On-the-Job Search in a Matching Model with Heterogenous Jobs and Workers", Juan J. Dolado, Marcel Jansen y Juan F. Jimeno.

2003-20: "Purchasing Power Parity Revisited", Simón Sosvilla-Rivero y Emma García

2003-19: "Credibility and Duration in Target Zones: Evidence from the EMS", Simón Sosvilla-Rivero y Francisco Pérez-Bermejo.

2003-18: “"Mondays at the sun": Unemployment, Time Use, and Consumption Patterns in Spain”, Namkee Ahn, Juan F. Jimeno y Arantza Ugidos.

2003-17: "Protecting Against Labour Market Risk: Employment Protection or Unemployment Benefits?", Tito Boeri, J. Ignacio Conde-Ruiz y Vincenzo Galasso.

2003-16: “What Social Security: Beveridgean or Bismarckian?", J. Ignacio Conde-Ruiz y Paola Profeta.

2003-15: "Forecasting the Dollar/Euro Exchange Rate: Can International Parities Help?", Simón Sosvilla-Rivero y Emma García.

\section{TEXTOS EXPRESS}

2003-01: “12+1 Reflexiones sobre 12+1 años de Gasto Farmacéutico”, José-Luis Perona Larraz. 